\title{
Impacts of Mannan oligosaccharides (MOS) on growth performance and gastrointestinal health of Nile tilapia (Oreochromis niloticus)

\author{
Ahmed H Al-Wakeel ${ }^{1}$, Eman Zahran ${ }^{1 *}$, Elsayed E Hafez ${ }^{2}$, Mohamed Hamed ${ }^{3}$, Viola H Zaki ${ }^{1}$
}

${ }^{1}$ Department of Internal Medicine, Infections and Fish Diseases, Faculty of Veterinary Medicine, Mansoura University, Mansoura 35516, Egypt.

${ }^{2}$ Department of Plant Protection and Biomolecular diagnosis, Arid Lands Cultivation Research Institute (ALCRI), Mubarak City for Scientific Research and Technology Applications, New Borg El Arab City, Alexandria 21934, Egypt.

${ }^{3}$ Pathology Department, Faculty of Veterinary Medicine, Mansoura University, Mansoura 35516, Egypt.

\section{ARTICLE HISTORY}

\section{Received: 15.08 .2019}

Revised: 23.08 .2019

Accepted: 24.08 .2019

Address correspondence to Dr. Eman

Zahran; Tel: +201211100560;

Fax: +20502200696

E-mail: emanzahran@mans.edu.eg

\section{ABSTRACT}

Objective: This study was undertaken to evaluate the potential role of Mannan oligosaccharides (MOS) on growth performance, liver and intestine tissue morphology, and gut microbiota of Nile tilapia (Oreochromis niloticus).

Design: Controlled study.

Animals: Three groups of Nile tilapia.

Procedures: Three diets were formulated to contain $0 \%$ of MOS 500 (MOS) as control (control), $0.05 \%$ of MOS plus adding MOS into water as well at level of $12.5 \mathrm{mg} / \mathrm{l}$ (MOS (feed +water), and the third group MOS was added only to water (MOS water) at the same level, and fed to Nile tilapia for 6 weeks.

Results: Simultaneous water and feed additives with (MOS feed+water) at $(0.05 \%$ of feed + $12.5 \mathrm{mg} / \mathrm{l}$ water) caused a significant increase in growth parameters (initial and final weight, weight gain (WG), specific growth rate (SGR), feed conversion ratio (FCR) and condition factor $(\mathrm{k})$, when compared to both MOS added only in tank water (MOS water) and control groups. In addition, MOS in both treatment types increased survival rates significantly compared to the control. Polymerase chain reaction and denaturing gradient gel electrophoresis (PCR-DGGE) analysis showed that a single species or species that contained chemically equivalent DNA dominated the intestinal tract of all Nile tilapia regardless of dietary treatment. While MOS had no adverse effect of intestinal histology, an increase in the villi length was recorded.

Conclusion and clinical relevance: Collectively, our results indicate that MOS added to feed and water could be used to enhance the growth performances, increase the survivability and exert beneficial effects on the gut microbiota of Nile tilapia.

Keywords: MOS, fish, histology, intestinal microbiota

\section{INTRODUCTION}

Aquaculture sector is the fastest growing food producing sector in the world and an important component in many poverty alleviation and food security programs [1]. Egypt is producing about $73.8 \%$ of total cultured fish in Africa and it is the eighth level all over the world because it produces about million tons of cultured fish that represents $1.54 \%$ of total cultured fish all over the world [2]. Nile tilapia is considered as one of the most important freshwater species for commercial aquaculture in Egypt, due to its high nutritional values, rapid growth rate and resistance to diseases leading to high level of production [3]

Biotechnology is one the important tools in modern technologies that potentiate a greater quantity and higher quality of production. One of the important pillars that play a key role in aquaculture is feeding in farming and the supplementation of some feed additives to a formula of balanced diet to reach higher growth.
Probiotics 'Eco-friendly agents' can be inserted into the aquaculture environment to compete with pathogenic bacteria and to boost the growth of cultured fish $[4,5]$.

Prebiotics can be considered as a growth factor to particular commensal bacterial organisms, that repress the adhesion and intrusion of pathogenic microorganisms in the colon epithelium by competing the same glycoconjugates found on the surface of epithelial cells; modifying the $\mathrm{pH}$ of the colon, preference the barrier function, improving the production of both mucus and short chain fatty acids and induce cytokine production [6].

Most Mannan oligosaccharides (MOS) products investigated in the aquaculture division derived from the external cell wall of yeast Saccharomyces cerevisiae (S. cerevisiae), where they are available in complex molecules connected to the protein fraction. MOS beneficial effects have been shown into different fish such as rainbow trout, gilt head sea bream, and juvenile striped catfish; where it is influenced 
the pathogen colonization and lead to enhancement of the immune response. Further, MOS plays important roles in growth promotion and improvement of food conversion, further; it acts as inhibitors of pathogen adherence to intestinal cells [7-10].

Gut microbial communities especially in fish are influenced by the dietary composition, which contribute in shaping this community and modulating the metabolism of key symbiont species with subsequent biological modification to the host [11-13]. In this regard, conventional culture dependent methods for identification of the fish microbiota that were typically relied on phenotypic and biochemical key characteristics [14], have recently been supplemented with molecular techniques that are based on sequencing of bacterial $16 \mathrm{~S}$ rRNA $V_{3}$ region using polymerase chain reaction (PCR) and denaturing gradient gel electrophoresis (PCR-DGGE) [15].

Therefore, the aim of this study was to evaluate the effect of MOS on growth performance parameters, survivability, diversity of gut microbiota and histopathological analysis of Nile tilapia (Oreochromis niloticus) with Mannan oligosaccharides (MOS 500).

\section{MATERIALS AND METHODS}

\subsection{Fish}

Nile tilapia, Oreochromis niloticus (weight $54.1 \pm 3.25 \mathrm{~g}$ ) were obtained from a private fish farm at Ad-Dakahliya province, Egypt. They were maintained aquarium tanks, which were provided with adequate aeration and under water internal power filter. $50 \%$ of the water was exchanged weekly to maintain water quality. The fish were fed twice-daily ad lib with a commercial diet at $25 \pm 2{ }^{\circ} \mathrm{C}$ during the feeding period. Fish were acclimatized for 2 weeks and during this period no clinical signs were ever observed.

\subsection{Mannan-oligosaccharide (MOS 500)}

MOS were purchased from a private company in Egypt. It is a kind of product that composed of $S$. cerevisiae cell wall extract (MOS at $202.5 \mathrm{~g}$, and $\beta-1,3(1,6)$ glucan at $135 \mathrm{~g})$.

\subsection{Preparation of diets and experimental design}

Three diets were formulated to contain $0 \%$ of MOS $500^{\circ}$ (MOS) as control (control), $0.05 \%$ of MOS plus adding MOS into water as well at level of $12.5 \mathrm{mg} / \mathrm{l}$ (MOS (feed +water), and the third group MOS was added only to water (MOS water) at the same level, as described in Table 1. All ingredients were mixed with oil and then adding water until stiff dough resulted. Each diet was then extruded through a mincer. The resulting strands were shadow-dried, broken up, sieved into pellets, and stored in plastic bags at $4^{\circ} \mathrm{C}$ until use. Fish were fed at $3 \%$ of their body weight throughout the experimental period into two equal rations at $09.00 \mathrm{hr}$ and $15.00 \mathrm{hr}$. Fish mortality was recorded daily.

One hundred and twenty-six Nile tilapia fish (Oreochromis niloticus) of $54.1 \pm 3.25 \mathrm{~g}$ were randomly distributed into three 80 -I aquarium tanks (14 fish/ tank); triplicate tanks were assigned per dietary regime (Total $\mathrm{N}=42$ fish). Fish were fed ad lib twice daily in equal rations at $09.00 \mathrm{hr}$ and $15.00 \mathrm{hr}$ for 6 weeks. All experimental procedures were in compliance with the Animal Care and Use Guidelines at Mansoura University and approved by the local Administrative Panel on Laboratory Animal Care Committee.

\subsection{Sample collection}

All fish were weighed at the start and at the end of the experiment (6 weeks), to calculate WG and SGR. Growth performance and feed utilization were assessed in terms of WG, SGR, $\mathrm{FCR}$, and condition factor (K). In addition, survival rate was calculated at the end of the experiment: survival $=(\mathrm{Nf} / \mathrm{NO}) * 100$; where N0 is the initial number of fish and $\mathrm{Nf}$ is the final number of fish.

\subsection{Growth performance measurements}

Growth performance parameters were calculated according to the following formulae:

SGR $(\%$ day -1$)=100[(\ln \mathrm{FW}-\ln \mathrm{IW}) / \mathrm{T}]$. Where $\mathrm{T}$ is the duration of feeding (days)

$\mathrm{FCR}(\mathrm{g} / \mathrm{g})=\mathrm{FI}(\mathrm{g}) / \mathrm{WG}(\mathrm{g})$. Where $\mathrm{Fl}$ is the Dry feed intake $(\mathrm{g})$

Condition factor $(\mathrm{K})=100 * \mathrm{~W} / \mathrm{Lt} 3$

\subsection{DNA extraction from Formalin-Fixed, Paraffin-Embedded (FFPE) Archival Tissues}

DNA was extracted from the FFPE tissues according to [16]. DNA extraction was done by phenol-chloroform (PC) extraction equal volume of phenol was added and vortexed. After spinning, the aqueous layer was transferred to a new tube. An equal volume of phenol-chloroform-isoamyl alcohol (25:25:1) was added. The product was vortexed and then spun for 5 minutes at $14000 \mathrm{rpm}$ in a microcentrifuge. The aqueous layer was transferred to a new tube. The estimated volume of the aqueous layer that was collected for DNA precipitation was $550 \mu \mathrm{l}$, and 0.1 volume of $3 \mathrm{M}$ sodium acetate and 1 volume of isopropanol were added. After thorough mixing, the tube was placed in a freezer for 30 minutes. The tube was then spun a maximum speed for 10 minutes at $4^{\circ} \mathrm{C}$ in a micro-centrifuge. The supernatant was discarded; the pellet was washed with $1 \mathrm{ml} 70 \%$ cold ethanol and spun at maximum speed for 10 minutes at $4^{\circ} \mathrm{C}$. The supernatant was discarded carefully, and the pellet dried. The pellet was then re-suspended with biological grade of $50 \mu \mathrm{ldH} 2 \mathrm{O}$.

\subsection{Polymerase chain reaction and denaturing gradient gel electrophoresis (PCR-DGGE)}

DNA was extracted from replicate samples from the control and treatment groups were pooled into single samples, each representing the microbial community of 6 fish per treatment using QIAamp ${ }^{\circledR}$ Stool Mini Kit (Qiagen) with a lysozyme pre-treatment prior to PCR amplification of V3 16S rRNA genes as previously described [17]. The DGGE was done using a DGGE-2001 system (C.B.S. scientific, CA, USA).10 $\mu \mathrm{L}$ of standardized PCR products were run on an $8 \%$ acrylamide gel with a denaturing gradient of $40-60 \%$ (where $100 \%$ denaturant is $7 \mathrm{M}$ urea and $40 \%$ formamide). All samples were run on the same gel to avoid issues of reproducibility. The gel was run at 65 $\mathrm{V}$ for $17 \mathrm{~h}$ at $60{ }^{\circ} \mathrm{C}$ in $1 \times \mathrm{TAE}$ buffer ( $66 \mathrm{mM}$ Tris, $5 \mathrm{mM}$ Na acetate, 1 mM EDTA). Visualization of the DGGE bands was achieved by the optimized silver staining method of Benbouza, Jacquemin [18]. The gel was scanned in a Bio-Rad universal hood II (Bio-Rad laboratories, Italy) and optimized for analyses by enhancing contrast and greyscale.

\subsection{Histopathological examination}

Intestinal samples were collected from four fish per tank ( $\mathrm{n}=$ 8 /group) at the end of the experimental trial, preserved in $10 \%$ neutral formaldehyde (in PBS) and processed for haematoxylin and eosin (H\&E) staining (light microscopy). Preparation of H\&E sections 
was carried out by the Histology laboratory, Faculty of Veterinary Medicine, Mansoura University. Light microscopy images were taken using XSZ-07 Series of biological microscope. Sections stained with haematoxylin and eosin were applied for semiquantitive histometric measurements; we measured from base of intestinal villi to tips of it using an image analysis (image J http://imagej.en.softonic.com) according to [19].

\subsection{Statistical analysis}

All data in this experiment were subjected to one-way analysis of variance using the SPSS computer software (SPSS version 17.0 for Windows). Differences between means were assessed by Duncan's multiple-range test and effects with a probability of $P<0.05$ were considered significant.

Table 1. Ingredient composition of the diets (\%).

\begin{tabular}{lll} 
Ingredient & \multicolumn{1}{c}{ Control } & MOS \\
Yellow Corn & 17.65 & 17.65 \\
Soybean meal & 20.50 & 20.50 \\
Fish meal & 25.00 & 25.00 \\
Wheat bran & 34.00 & 33.95 \\
Corn gluten meal & 1.00 & 1.00 \\
Sunflower Oil & 0.85 & 0.85 \\
Vitamins \& mineral premix & \\
Salt & 0.50 & 0.50 \\
MOS $500^{\circ}$ & 0.50 & 0.50 \\
& 0.00 & 0.05
\end{tabular}

${ }^{a}$ Trace minerals \& vitamins premixes were prepared to cover the levels of the micro minerals \&vitamins for tilapia fish as recommended by (NRC, 1993). Vitamins premix (IU or $\mathrm{mg} \mathrm{kg}^{-1}$ diet); vit. A 5000, vit. D3 1000, vit. E 20, vit. K3 2, vit. B1 2, vit. B2 5, vit. B6 1.5, vit. B12 0.02, Pantothenic acid 10, Folic acid 1, Biotin 0.15, Niacin 30. Mineral mixture (mg/kg diet); Fe 40, Mn 80, Cu 4, Zn 50, I 0.5, Co 0.2 \& Se 0.2 .

\section{RESULTS}

\subsection{Effect of MOS on growth performance parameters}

MOS dietary and water supplementation after 6 weeks' experimental period revealed that the FW was significantly higher (83.83 \pm 1.22) in MOS (water+feed) group than both the control (72.13 \pm 2.14), and MOS (water) groups (76.68 \pm 1.95). This consequently reflected in higher WG, better SGR, FCR, and $\mathrm{K}$ factor of fish treated with MOS (water+feed) that were significantly improved compared to the other two groups (Fig. 1\& 2)

\subsection{Effect of MOS on survival Rate}

MOS treatment either in water or in both water and feed showed improvement in the survival rate, which was significantly higher in these groups than the control (Fig. 1).

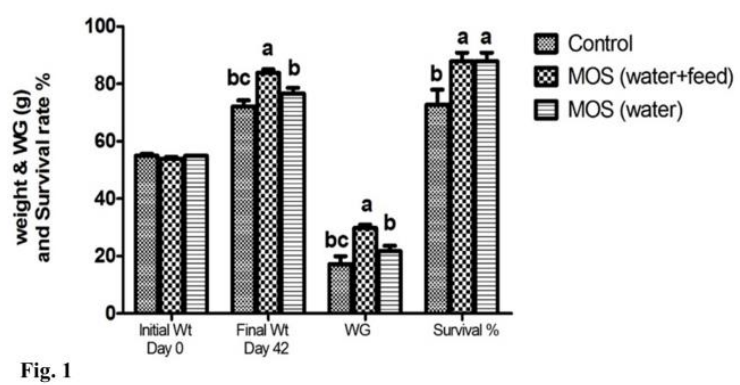

Figure 1. Growth performance parameters (IW, FW, WG, and survival \%) in Nile tilapia ( $O$. niloticus) treated with MOS in water + feed and in water only for 6 weeks. Data is expressed as the mean of three fish \pm SEM. Values with a different letter superscript are significantly different between groups $(P<0.05)$

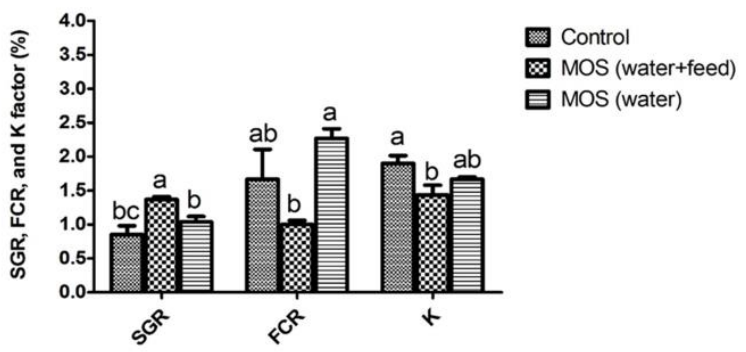

Fig. 2

Figure 2. Growth performance parameters (FW, SGR, FCR, and $\mathrm{K}$ factor) in Nile tilapia ( $O$. niloticus) treated with MOS in water + feed and in water only for 6 weeks. Data is expressed as the mean of three fish \pm SEM. Values with a different letter superscript are significantly different between groups $(P<0.05)$.
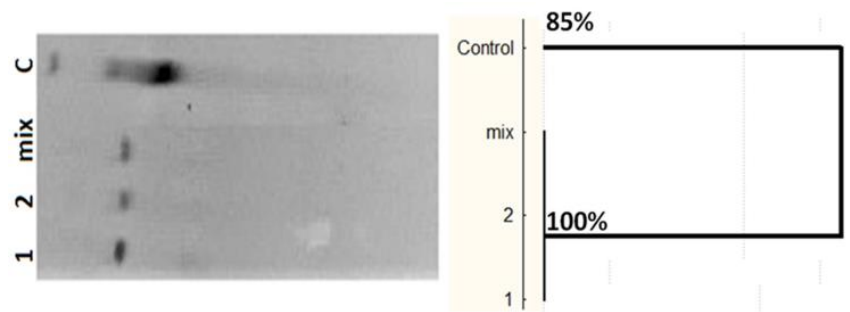

Fig. 3

Figure 3. Phylogenetic analysis of Denaturing gradient gel electrophoresis of bacterial 165 rDNA amplicons from Nile tilapia FFPE intestinal sections. The \% on branches indicates percentage similarity coefficients. $\mathrm{C}=$ control, $1=$ MOS in water + feed, $2=$ MOS in water only, and mix = mixture from both group together.

\subsection{Polymerase chain reaction and denaturing gradient gel electrophoresis (PCR-DGGE)}

Microbial coefficient (\% SC) was used to determine how closely related microbial populations were to one another, with SC\% values above $95 \%$ indicated populations are identical. \% SC values between 80 and $95 \%$ indicating the populations were related or closely related and values below $80 \%$ indicated that microbial populations were considered distinct. DGGE analysis showed that a single species or species that contained chemically equivalent DNA dominated the intestinal tract of all Nile tilapia regardless of dietary treatment (Fig. 3).

\subsection{Histopathological analysis}

There were no significant differences in the villi length between control and treatment groups at 4 weeks, while, there were a significant increase in the villi length in group treated with MOS in 
water and feed compared to control. However, there were no significant changes between MOS in water and feed compared to both MOS in water and control groups (Fig. 6). Liver is showing normal hepatopancreas and Normal hepatocytes and also, intestine is showing normal mucosa with normal intestinal villi; since there is no variation has been observed in the histology of liver and intestine was revealed between experimental groups compared to the control one (Fig. 7 and 8).

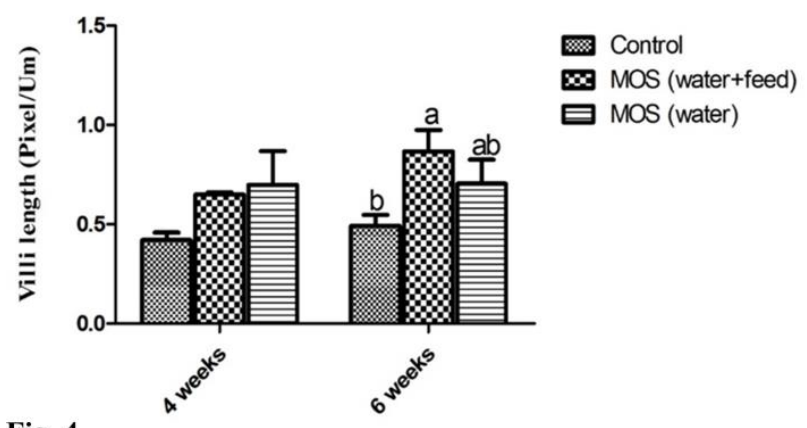

Fig. 4

Figure 4. Intestinal villi length in Nile tilapia (O. niloticus) treated with MOS in water + feed and in water only for 6 weeks. Data is expressed, as the mean of eight fish \pm SEM. Values with a different letter superscript are significantly different
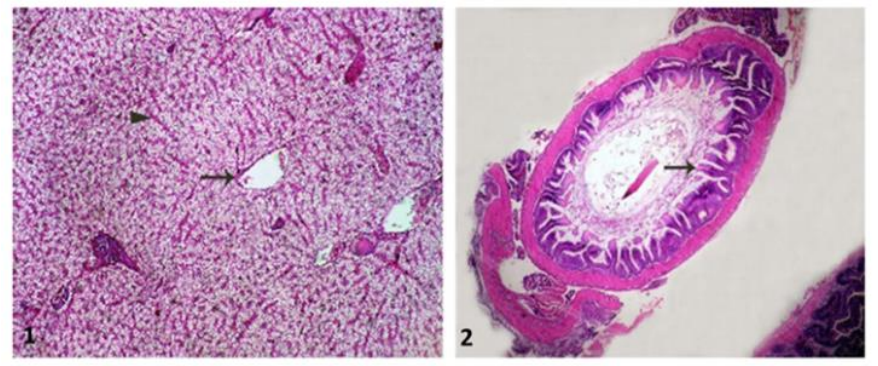

Figure 5. Liver and intestine of Nile tilapia fed control basal diet showing: 1) Liver with normal hepatopancreas and normal hepatocytes. 2) Intestine with normal mucosa and intestinal villi.

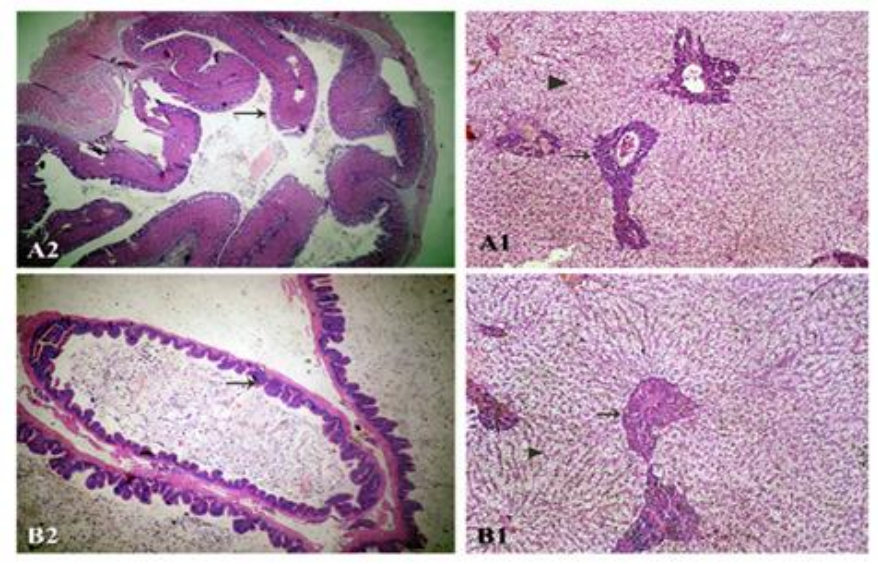

Figure 6. Intestine and liver of Nile tilapia fed MOS in water + feed (A); and in water (B) after 4 weeks showing: 1) Intestine with normal mucosa and normal intestinal villi. 2) Liver with normal hepatopancreas and normal hepatocytes.
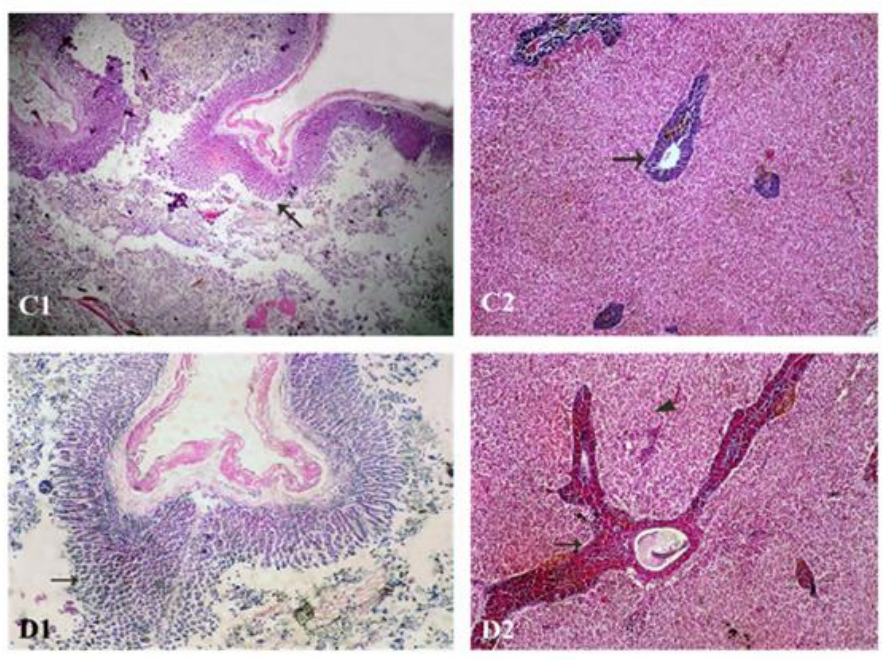

Figure 7. Intestine and liver of Nile tilapia fed MOS in water + feed (C); and in water (D) after 6 weeks showing: 1) Intestine with normal mucosa and normal intestinal villi. 2) Liver with normal hepatopancreas and normal hepatocytes.

\section{DISCUSSION}

Nowadays, great attention has been paid to the use of prebiotics in aquaculture. MOS is one of these prebiotics that widely used in fish for their ability to promoting health and control of potential diseases, in addition to their positive effect on gut health [20-22]. However, the ultimate outcomes of prebiotics on growth performance are dependent on prebiotic source, fish species, and other factors, including diet composition.

In the present study, MOS administration in feed and water simultaneously showed increased in all growth performances including, (FW, WG, SGR, FCR, and $\mathrm{K}$ factor) compared to the other two groups. However, MOS treated water group was not significantly different from control but it still showed nominal increase than the control level.

Many literatures reported the enhancement of growth performance parameters in different fish species; and this could be attributed to several concerns such as changes in gut microbiota abundance or diversity, improved digestive enzymatic activity, improved gut morphology, or modifications in intermediary metabolism [23-25]. These variations among these reported results might be related to many factors such as the dose, characteristics of the used prebiotics; and fish species, the water temperature, methods of application, diet composition; and the length of the feeding period.

Studies by others have also shown similar effects of MOS on growth performance and feed efficiency; at levels from 1 to $1.5 \mathrm{~g} / \mathrm{kg}$ diet in Common carp fingerlings for 8 weeks [26]. In the same line, Nile tilapia fed galactooligosaccharide at level of $5 \%$ revealed significant increases in the specific growth rate and weight gain [27]. Similarly, dietary MOS at 20 and 40g in European seabass, showed promotion in amino acid absorption that lead to improvement in growth; especially at level of $40 \mathrm{~g} / \mathrm{kg}$ [28]. Rainbow trout was fed MOS at level of $2 \mathrm{~g} / \mathrm{kg}$ diet for 90 days lead to growth enhancement [29]. While, rainbow trout fed on lower dietary level of 1.5, 3 and 4 $\mathrm{g} / \mathrm{kg}$, resulted in significant increase in the growth with no obvious effect on FCR [30]. Another study on rainbow trout fed on $4 \mathrm{~g}$ $\mathrm{MOS} / \mathrm{kg}$ diet showed increase in growth parameters [31]. MOS at 
levels 2 and $4 \mathrm{~g}$ MOS/kg diet showed growth parameter improvement [32]. In beluga juvenile fed on inactive yeast or a blend of MOS and $\beta$ glucan, a significant improvement in in growth performance; FCR, SGR, weight gain and final weight compared to fish fed on basal diet $[33,34]$.

Nile tilapia juvenile fed MOS at different levels showed increase in the weight gain and that level of $0.4 \%$ MOS recorded the highest weight gain, while, feed consumption was decreased with the increase of the MOS level in diet [35].

The probiotic (bacteria Lactobacillus plantarum) was used as a water additive in three concentrations T1 (10 $\mathrm{cfu} / \mathrm{l}$ water), T2 (10 $\mathrm{cfu} / \mathrm{l}$ water) and T3 (109 $\mathrm{cfu} / \mathrm{lwater})$ in prawn juvenile for 90 days; exhibited a significant increase in the growth parameters such as final mean weight, weight gain \% and SGR; also feed utilization parameters such as FCR and PER significantly improved in T3 compared to the control [36]. Previous study was undertaken in Nile tilapia juveniles to investigate three probiotics as water additives (final concentration of $1 \times 10^{7} \mathrm{cfu} / \mathrm{ml}$ every 2 days), probiotics were Bacillus subtilis B10, Bacillus coagulans B16 and Rhodo-pseudomonas palustris G06; results showed a significant improvement in final weight, daily weight gain and specific growth rate in groups used both Bacillus coagulans B16 and Rhodo-pseudomonas palustris G06 compared to the control group, while Bacillus subtilis B10 showed no significant effect compared to control group [37].

In the present study, DGGE analysis showed that a single species or species that contained chemically equivalent DNA dominated the intestinal tract of all Nile tilapia regardless of dietary treatment. Our results were in agreement when compared with that of other fish species [38, 39]. Similarly, red drum fish fed two prebiotics GroBiotic$A$ and inulin showed no effect of the dietary prebiotics as the microbial community appeared to be dominated by a single organism with very low diversity when compared with other livestock and fish species by (DGGE) analysis of the gastrointestinal tract microbial community [40]. In the same context, PCR-DGGE analysis from Nile tilapia fingerlings administered Bacillus cereus as both water and feed additive showed dissimilar DGGE patterns, and showed that $B$. cereus supplementation in the feed and water affected the autochthonous gut bacteria community of tilapia and stimulated various potentially beneficial bacteria [41].

On the other hand, another study conducted by Guerreiro, Serra [24] reported that DGGE analysis of white sea bream (Diplodus sargus) juvenile fed prebiotic supplemented diets had no effect of the dietary prebiotics and the majority of the dominant allochthonous bacteria detected were most closely related to uncultured bacteria previously isolated from the environment, plants or other animals. In the same line, other studies have shown more than one band through using DGGE profile in many species as when compared with haddock larvae, Melanogrammus aeglefinus, coho salmon, Oncorhynchus kisutch, and rainbow trout, Oncorhynchus mykiss [39, 42,43 ]. It is possible that other bands were present at levels much lower than the dominant band, but it is unlikely that these species would play a significant role in the microbial intestinal tract community.

It is well known that gut microbiota may change with time [44], these variations in diversity of gastrointestinal tract microbial community through DGGE analysis are controversial and it could be related to some factors including, water quality, and low microbial diversity. Other concern might be that the intestinal microbial community of Nile tilapia kept in the closed static system did not have the chance to mature and thus provide the diversity found at later life stages.

In the present study, MOS administration in feed and water simultaneously showed improvement in survival rates compared to the control group. However, MOS treated water group was not significantly different from group MOS in both feed and water but with nominal increase compared to control. Our results are coincided with many previous studies that have shown increased survival rates upon feeding MOS; in rainbow trout fed $2 \mathrm{~g} \mathrm{MOS} / \mathrm{kg}$ diet for 90 days in comparison to control group [29]. In hybrid tilapia fed on different levels of MOS for 58 days; showed higher survival rate compared to fish fed on basal diet [45]. In common carp fry fed on MOS supplemented diet 0,5 and $10 \%$ for 7 weeks showed significant increase in survival rate compared to fry fed on basal diet [46] in Labeo rohita fingerlings MOS fed group, revealed that the highest survival rate when supplemented at $1 \%$ [47]. In same line, Survival rate significantly improved in Penaes semisulcatus post larvae fed $3 \mathrm{~g}$ MOS/kg die for 48 days [48]. Beluga sturgeon juvenile fed on different levels of oligofructos for 7 weeks; showed higher survival rate [33].

In the current study, no significant differences in the villi length between control and treatment groups at 4 weeks, while, there were a significant increase in the villi length in group treated with MOS in water and feed compared to control. However, there were no significant changes between MOS in water and feed compared to both MOS in water and control groups. Additionally, no variations have been observed in the histology of liver and intestine between experimental groups compared to the control one. Previous studies have also shown similar effects in different fish species, for example; cobia larvae fed on artemia and rotifers enriched with MOS showed clear improvement to the microvilli alignment, density and length compared to larvae fed on basal diet [49]. Rainbow trout and gilthead sea bream fed on a diet supplemented with MOS exhibited increase in the absorptive surface area in posterior gut, also both density and length of microvilli were increased, besides, significant increase in the perimeter ratio of anterior and posterior parts of the intestine in Sole fish $[8,9,20]$. In Penaes semisulcatus post larvae fed MOS revealed on transversal sections that hepatopancreatic tissues showed normal findings in all study groups which mean no change between groups [48].

\section{Conclusion}

In conclusion, our study suggested that using MOS as prebiotic; potentially improved growth performance parameters, survival rates; besides the improvement of gut morphology and microbiota that could be beneficial to fish health. Taken together these results, we conclude that however, treatment with the prebiotic, MOS, in feed and water, could be used to enhance the measured parameters of tilapia, using MOS as dietary additives will be more applicable and economic in feed than in both water and feed.

\section{Conflict of interest}

Authors declare that they have no conflict of interest

\section{Acknowledgement}

This research was supported by Laboratory of Fish Diseases, Department of Internal Medicine, Infections and Fish Diseases, 
Faculty of Veterinary Medicine; and Department of Plant Protection and Biomolecular Diagnosis, Arid Lands Cultivation Research Institute (ALCRI), Mubarak City for Scientific Research and Technology Applications.

\section{Author contributions}

A. A performed the experiment and drafted the MS; E. H. carried out DNA extraction from Formalin-Fixed, Paraffin-Embedded (FFPE) Archival Tissues and DGGE analysis, M. H. assist histopathology; E.Z. performed the statistical analysis, reviewed and edited MS; E.Z. and V. Z. supervised the whole research work and revised the MS.

\section{REFERENCES}

[1] FAO I, UNICEF. WFP, WHO (2017) The state of food security and nutrition in the world 2017. Building resilience for peace and food security FAO, Rome URL: http://www fao org/3/a-i7695e pdf (Accessed 16 May 2018). 2017.

[2] FAO F. Agriculture Organization of the United Nations. 2012. FAO statistical yearbook. 2012

[3] Matter AF, El Asely AM, Shaheen AA, El-Gawad EAA, El-Abd H, Abbass AA. Phenotypic and molecular characterization of bacterial pathogens isolated from diseased freshwater fishes. Int J Fish Aquat 2018; 6: 34-41.

[4] Bruce TJ, Brown ML. A review of immune system components, cytokines, and immunostimulants in cultured finfish species. Open J Anim Sci 2017;7:267.

[5] Nayak S. Probiotics and immunity: a fish perspective. Fish Shellfish Immun 2010;29:2-14

[6] Akhter N, Wu B, Memon AM, Mohsin M. Probiotics and prebiotics associated with aquaculture: a review. Fish Shellfish Immun 2015;45:73341.

[7] Bavington C, Page C. Stopping bacterial adhesion: a novel approach to treating infections. Respiration 2005;72:335-44.

[8] Dimitroglou A, Merrifield D, Moate R, Davies S, Spring P, Sweetman J, et al. Dietary mannan oligosaccharide supplementation modulates intestinal microbial ecology and improves gut morphology of rainbow trout, Oncorhynchus mykiss (Walbaum). J Anim Sci 2009;87:3226-34.

[9] Dimitroglou A, Merrifield DL, Spring P, Sweetman J, Moate R, Davies SJ. Effects of mannan oligosaccharide (MOS) supplementation on growth performance, feed utilisation, intestinal histology and gut microbiota of gilthead sea bream (Sparus aurata). Aquacult 2010;300:182-8.

[10] Akter MN, Sutriana A, Talpur AD, Hashim R. Dietary supplementation with mannan oligosaccharide influences growth, digestive enzymes, gut morphology, and microbiota in juvenile striped catfish, Pangasianodon hypophthalmus. Aquacult Int 2016;24:127-44.

[11] Sullam KE, Essinger SD, Lozupone CA, O'CONNOR MP, Rosen GL, Knight R, et al. Environmental and ecological factors that shape the gut bacterial communities of fish: a meta-analysis. Mol Ecol 2012;21:3363-78.

[12] Askarian F, Sperstad S, Merrifield DL, Ray AK, Ring $\varnothing$ E. The effect of different feeding regimes on enzyme activities of gut microbiota in Atlantic cod (Gadus morhua L.). Aquacult Res 2013;44:841-6.

[13] Ring $\varnothing E$, Zhou Z, He S, Olsen RE. Effect of stress on intestinal microbiota of Arctic charr, Atlantic salmon, rainbow trout and Atlantic cod: a review. African J Microbiol Res 2014;8:609-18.

[14] Li Y, Yang P, Zhang Y, Ai Q, Xu W, Zhang W, et al. Effects of dietary glycinin on the growth performance, digestion, intestinal morphology and bacterial community of juvenile turbot, Scophthalmus maximus L. Aquacult 2017;479:125-33.

[15] Yang G, Bao B, Peatman E, Li H, Huang L, Ren D. Analysis of the composition of the bacterial community in puffer fish Takifugu obscurus. Aquacult 2007;262:183-91.

[16] Santos MC, Saito CP, Line SR. Extraction of genomic DNA from paraffinembedded tissue sections of human fetuses fixed and stored in formalin for long periods. Pathol Res Pract 2008;204:633-6.

[17] Merrifield DL, Burnard D, Bradley G, Davies SJ, Baker RTM. Microbial community diversity associated with the intestinal mucosa of farmed rainbow trout (Oncoryhnchus mykiss Walbaum). Aquacult Res 2009;40:1064-72.

[18] Benbouza H, Jacquemin J-M, Baudoin J-P, Mergeai G. Optimization of a reliable, fast, cheap and sensitive silver staining method to detect SSR markers in polyacrylamide gels. Biotechnol Agron Soc 2006;10:77-81.

[19] Bancroft JD, Gamble M. Theory and practice of histological techniques. In: ed. t, editor.: London: Churchill Livingstone; 2008.

[20] Dimitroglou A, Moate R, Janssens T, Spring P, Sweetman J, Davies S. Field observations on the effect of a mannan oligosaccharide on mortality and intestinal integrity of sole (Solea senegalensis, Kaup) infected by Photobacterium damselae subsp. piscicida. J Aquac Res Dev 2011;1:013.

[21] Merrifield DL, Bradley G, Baker RTM, Davies SJ. Probiotic applications for rainbow trout (Oncorhynchus mykiss Walbaum) II. Effects on growth performance, feed utilization, intestinal microbiota and related health criteria postantibiotic treatment. Aquacult Nutr 2010;16:496-503.

[22] Ring $\varnothing \mathrm{E}$, Olsen R, Gifstad T, Dalmo R, Amlund $\mathrm{H}$, Hemre $\mathrm{Gl}$, et al. Prebiotics in aquaculture: a review. Aquacult Nutr 2010;16:117-36.

[23] Anguiano M, Pohlenz C, Buentello A, Gatlin DM. The effects of prebiotics on the digestive enzymes and gut histomorphology of red drum (Sciaenops ocellatus) and hybrid striped bass (Morone chrysopsx $M$. saxatilis). Br J Nutr 2013;109:623-9.

[24] Guerreiro I, Serra C, Pousão-Ferreira P, Oliva-Teles A, Enes P. Prebiotics effect on growth performance, hepatic intermediary metabolism, gut microbiota and digestive enzymes of white sea bream (Diplodus sargus). Aquacult Nutr. 2018;24:153-63.

[25] Hoseinifar SH, Soleimani N, Ring $\varnothing$ E. Effects of dietary fructooligosaccharide supplementation on the growth performance, haematoimmunological parameters, gut microbiota and stress resistance of common carp (Cyprinus carpio) fry. Br J Nutr 2014;112:1296-302.

[26] Ebrahimi G, Ouraji H, Khalesi M, Sudagar M, Barari A, Zarei Dangesaraki $\mathrm{M}$, et al. Effects of a prebiotic, Immunogen ${ }^{\circledR}$, on feed utilization, body composition, immunity and resistance to Aeromonas hydrophila infection in the common carp Cyprinus carpio (Linnaeus) fingerlings. J Anim Physiol Nutr 2012;96:591-9.

[27] Plongbunjong V, Phromkuntong W, Suanyuk N, Viriyapongsutee $B$, Wichienchot S. Effects of prebiotics on growth performance and pathogenic inhibition in sex-reversed red tilapia (Oreochromis niloticusx Oreochromis mossambicus). Thai J Agricult Sci 2011;44:162-7.

[28] Torrecillas S, Makol A, Caballero M, Montero D, Robaina L, Real F, et al. Immune stimulation and improved infection resistance in European sea bass (Dicentrarchus labrax) fed mannan oligosaccharides. Fish Shellfish Immun 2007;23:969-81.

[29] Staykov Y, Spring P, Denev S, Sweetman J. Effect of a mannan oligosaccharide on the growth performance and immune status of rainbow trout (Oncorhynchus mykiss). Aquacult International 2007;15:153-61.

[30] Ye JD, Wang K, Li FD, Sun YZ. Single or combined effects of fructo-and mannan oligosaccharide supplements and Bacillus clausii on the growth, feed utilization, body composition, digestive enzyme activity, innate immune response and lipid metabolism of the Japanese flounder Paralichthys olivaceus. Aquacult Nutr 2011;17:e902-e11.

[31] Rodrigues-Estrada U, Satoh S, Haga Y, Fushimi H, Sweetman J. Studies of the effects of mannan-oligosaccharides, Enterococcus faecalis, and poly hydrobutyric acid as immune stimulant and growth promoting ingredients in rainbow trout diets. 5th World Fisheries Congress, Yokohama, Japan October 20-25. 2008, 158p.

[32] Samrongpan C, Areechon N, Yoonpundh R, Sirsapoome P. Effects of mannan-oligosaccharide on growth, survival and disease resistance of Nile tilapia (Oreochromis niloticus linnaeus) fry. 8th International Symposium on Tilapia in Aquaculture: Cairo Egypt; Oct 12 (Vol. 345353). 2008.

[33] Hoseinifar SH, Mirvaghefi A, Merrifield DL. The effects of dietary inactive brewer's yeast Saccharomyces cerevisiae var. ellipsoideus on the growth, physiological responses and gut microbiota of juvenile beluga (Huso huso). Aquacult 2011;318:90-4.

[34] Ta'ati R, Soltani M, Bahmani M, Zamini A. Effects of the prebiotics Immunoster and Immunowall on growth performance of juvenile beluga (Huso huso). J Appl Ichthyol 2011;27:796-8. 
[35] Sado RY, Bicudo ÁJDA, Cyrino JEP. Feeding dietary mannan oligosaccharides to juvenile Nile tilapia, Oreochromis niloticus, has no effect on hematological parameters and showed decreased feed consumption. J World Aquacult Soc 2008;39:821-6.

[36] Dash G, Raman RP, Prasad KP, Marappan M, Pradeep MA, Sen S. Evaluation of Lactobacillus plantarum as a water additive on host associated microflora, growth, feed efficiency and immune response of giant freshwater prawn, Macrobrachium rosenbergii (de Man, 1879). Aquacult Res 2016;47:804-18.

[37] Zhou X, Tian Z, Wang Y, Li W. Effect of treatment with probiotics as water additives on tilapia (Oreochromis niloticus) growth performance and immune response. Fish Physiol Biochem 2010;36:501-9.

[38] Ring $\varnothing$ E, Sperstad S, Myklebust R, Mayhew TM, Olsen RE. The effect of dietary inulin on aerobic bacteria associated with hindgut of Arctic charr (Salvelinus alpinus L.). Aquacult Res 2006;37:891-7.

[39] Plante S, Pernet F, Haché R, Ritchie R, Ji B, Mclntosh D. Ontogenetic variations in lipid class and fatty acid composition of haddock larvae Melanogrammus aeglefinus in relation to changes in diet and microbial environment. Aquacult 2007;263:107-21.

[40] Burr G, Gatlin III DM, Hume M. Effects of the prebiotics GroBiotic ${ }^{\circledR}$-A and inulin on the intestinal microbiota of red drum, Sciaenops ocellatus. J World Aquacult Soc 2009;40:440-9.

[41] Wang M, Liu G, Lu M, Ke X, Liu Z, Gao F, et al. Effect of Bacillus cereus as a water or feed additive on the gut microbiota and immunological parameters of Nile tilapia. Aquacult Res 2017;48:3163-73.

[42] Guerreiro I, Serra C, Pousão-Ferreira P, Oliva-Teles A, Enes P. Prebiotics effect on growth performance, hepatic intermediary metabolism, gut microbiota and digestive enzymes of white sea bream (Diplodus sargus). Aquacult Nutr 2018;24:153-63.

[43] Heikkinen J, Vielma J, Kemiläinen O, Tiirola M, Eskelinen P, Kiuru T, et al. Effects of soybean meal based diet on growth performance, gut histopathology and intestinal microbiota of juvenile rainbow trout (Oncorhynchus mykiss). Aquacult 2006;261:259-68.

[44] Romero J, Navarrete P. 16S rDNA-based analysis of dominant bacterial populations associated with early life stages of coho salmon (Oncorhynchus kisutch). Microbial ecology 2006;51:422-30.

[45] Kühlwein H, Emery M, Rawling M, Harper G, Merrifield D, Davies S. Effects of a dietary $\beta-(1,3)(1,6)$-D-glucan supplementation on intestinal microbial communities and intestinal ultrastructure of mirror carp (Cyprinus carpio L.). J Appl Microbiol 2013;115:1091-106.

[46] He S, Xu G, Wu Y, Weng H, Xie H. Effects of IMO and FOS on the growth performance and non-specific immunity in hybrid tilapia. Chinese Feed 2003;23:14-5.

[47] Eshaghzadeh $\mathrm{H}$, Hoseinifar S, Vahabzadeh $\mathrm{H}$, Ring $\varnothing$ E. The effects of dietary inulin on growth performances, survival and digestive enzyme activities of common carp (Cyprinus carpio) fry. Aquacult Nutr 2015;21:242-7.

[48] Andrews SR, Sahu NP, Pal A, Kumar S. Haematological modulation and growth of Labeo rohita fingerlings: effect of dietary mannan oligosaccharide, yeast extract, protein hydrolysate and chlorella. Aquacult Res 2009;41:61-9.

[49] Genc M, Aktas M, Genc E, Yilmaz E. Effects of dietary mannan oligosaccharide on growth, body composition and hepatopancreas histology of Penaeus semisulcatus (de Haan 1844). Aquacult Nutr 2007;13:156-61.

[50] Salze G, McLean E, Schwarz M, Craig S. Dietary mannan oligosaccharide enhances salinity tolerance and gut development of larval cobia. Aquacult 2008;274:148-52. 